\title{
Effect of Hydroalcoholic Extract of Capparis decidua (Forssk.) Edgew on Sexual Behavior of Male Rats
}

\author{
Prashant Kumar Dhakad ${ }^{1, *}$, Pramod Kumar Sharma1, Sokindra Kumar ${ }^{2}$ \\ ${ }^{1}$ Department of Pharmacy, Galgotias University, Greater Noida, 201310, Uttar Pradesh, India \\ ${ }^{2}$ R.V. Northland Institute (RVNI), Chithera, Dadri, Greater Noida-II, 203207, Uttar Pradesh, India
}

Copyright $(\mathrm{C} 2018$ by authors, all rights reserved. Authors agree that this article remains permanently open access under the terms of the Creative Commons Attribution License 4.0 International License.

\begin{abstract}
Capparis decidua has traditionally been recommended as an aphrodisiac agent. Although, it's medicinal use has not been scientifically proved. The present study therefore evaluated the effects of hydroalcoholic extract of $C$. decidua roots, stem and leaf on sexual behavior in normal male rats. The hydroalcoholic extract of $C$. decidua was administered $(100 \mathrm{mg} / \mathrm{kg}$, $200 \mathrm{mg} / \mathrm{kg}$ ) to different groups of male wistar rats for 28 days. The female rats were brought in estrous phase before the mating in each group of male rats. Standard group was administered sildenafil citrate at $5 \mathrm{mg} / \mathrm{kg}$ orally for 28 days. Control group was administered only distilled water. All the experimental groups i.e C. decidua $100 \mathrm{mg} / \mathrm{kg}, 200$ $\mathrm{mg} / \mathrm{kg}$, per se group (only C. decidua $200 \mathrm{mg} / \mathrm{kg}$ ), standard group(sildenafil citrate $5 \mathrm{mg} / \mathrm{kg}$ ) were compared with the control group for parameters evaluated for sexual behavior study. C. decidua at $100 \mathrm{mg} / \mathrm{kg}, 200 \mathrm{mg} / \mathrm{kg}$, and per se treated groups produced significant arousal of sexual activity in male rats. They significantly increased the frequencies of mount, intromission frequency. The mount latency and intromission latency were significantly reduced but ejaculation latency was prolonged significantly. The results indicated that hydroalcoholic extract of $C$. decidua enhanced sexual behaviour in male rats. The enhanced sexual behavior in male rats at the doses of 100 and $200 \mathrm{mg} / \mathrm{kg}$ body weight may be due to the presence of phytochemicals like alkaloids, saponins, flavonoids as these phytochemicals has role in increasing sexual strength, androgen enhancing, and antioxidant activity.
\end{abstract}

Keywords Aphrodisiac, Capparis decidua, Sexual Behavior, Sildenafil Citrate, Phytochemicals

\section{Introduction}

Sexual intercourse holds importance in biological and social relationships in human life. Male erectile dysfunction influences not only sexual behavior, but also quality of life. Erectile dysfunction also called as "impotence", is the repeated failure to get or keep up a sufficiently firm erection of penis to allow coitus[1]. The ascent in populace in developing countries is overwhelming and this strengthens the requirement for viable anti-conception medication measures. The synthetic drugs available in market for birth control show severe side effects like hormonal imbalance, increased blood pressure, and weight gain and increased risk of cancer. Subsequently, it is necessary to change these drugs by safe and effective plant-origin drugs [2]. Caper is a perennial shrub and is the common name of the Capparis genus belonging to Capparidaceae family. This genus contains several plant species (about 250) [3]. Capparis decidua (Forsk.) Edgew. (Family: Capparidaceae) is a xerophytic shrub, discovered broadly in the western parts of Pakistan, India and a portion of the Asian nations[4]. It is broadly distributed in surrendered dry terrains presented to extraordinary radiations where yearly temperatures run from 18 to $48^{\circ} \mathrm{C}$. It is a little bush reaching up to height of $5 \mathrm{~m}$ and possess dense and thin branches [5]. In light of its xerophytic versatile nature this plants develops well under the brutal climatic states of parched locales. Roots of $C$. decidua have been utilized as an aphrodisiac agent by traditional people in dry regions of Thar deserts [6]. The dried fruits are used as an ingredient in diabetes treating medications and inexperienced green berries are utilized in meals preparations such as pickles owing to the historical perception that it possesses medicinal properties [4]. The roots, flowers, and fruits of $C$. decidua have been in use on the grounds that it acts against infectious diseases without any side effects. Roots acts as carminative, thermogenic, expectorant, anodyne, anthelmintic, sudorific, stimulant, digestive, antibacterial, and useful in arthritis, constipation, dysmenorrhoea, odontalgia, dyspepsia, amenorrhoea and lumbago [6]. Enough phytochemical work has been done as such far on $C$. decidua, which has been accounted for containing $\beta$-sitosterols, aliphatic constituents, indoles, isocodonocarpine, oxygenated heterocyclic compounds, 
diterpene alcohol, tannins, $\beta$-carotene, minerals, vitamin $C$ and large quantities of alkaloids, e.g., stachydrine and spermidine alkaloids [2]. The aim of present work is to investigate the effect of hydroalcoholic extract of $C$. decidua on sexual behavior of male rats using multiple parameters like ejaculation latency, intromission latency, intromission frequency, mount latency, mount frequency.

\section{Material and Methods}

\subsection{Plant Material and Extraction}

The complete plant of Capparis decidua was collected fresh from Jaipur, Rajasthan, India. The plant was taxonomically identified and authenticated by Prof. Kailash Agrawal, Convener Herbarium committee, Department of Botany, University of Rajasthan, Jaipur. A voucher specimen was deposited at the herbarium of the Department of Botany, University of Rajasthan, Jaipur, Rajasthan, India (R.No.-RUBL 211645). C. decidua root, stem and leaves were washed with tap water followed by distilled water and then cut and dried under the shade. The dried plant parts were comminuted into moderately coarse powder and passed through sieve no. 40 , stored in a tightly closed container. The dried and powdered plant material was Soxhlet extracted with water and ethyl alcohol (99.9\%) in the ratio of 30:70. The extraction was carried out for $24 \mathrm{~h}$ at room temperature with mild shaking. The extract was filtered and concentrated at $48^{\circ} \mathrm{C}$ by keeping on a water bath and weight of residue was recorded. The percentage yield of hydroalcoholic extract was found to be $42.8 \%$. The collected extract was stored in a sterile container for further use.

\subsection{Experimental Animals}

Healthy Albino Wistar rats of both sexes weighing 150-250 g were obtained from Central Animal Facility AIIMS New Delhi. The experimental protocol was approved by Institutional Animal Ethics Committee CPCSEA No. - 1149/PO/ERe/07/CPCSEA. Animals were housed under standard conditions of temperature $\left(24 \pm 2^{\circ} \mathrm{C}\right)$ and relative humidity (30\%-70\%) with 12:12 light: dark cycle. The animals were given standard pellet diet and water ad libitum.

\subsection{Chemicals}

The hydroalcoholic extract of C. decidua was dissolved in the distilled water and orally administered to the test groups. Sildenafil citrate was procured from the Cadila Pharmaceuticals Limited, Ahmadabad, Gujarat, India as a generous gift. Ethinyl oestradiol and progesterone were purchased from Sigma Chemical Co. ,USA).

\subsection{Phytochemical Screening}

The hydroalcoholic extract of $C$. decidua was analyzed for the presence of pharmacologically active constituents such as phenols, alkaloids, saponins, flavonoids, terpenoids, cardiac glycosides, steroids, tannins and carbohydrates [7]. Phytochemical results have been shown in Table 1 .

\subsection{Animal Groups and Extract Administration}

Thirty male rats were randomly divided into five groups of 6 rats each and were orally administered the following: Group 1 (control), $10 \mathrm{ml} / \mathrm{kg}$ of distilled water orally in sexually active male rats; group 2 (standard), suspension of sildenafil citrate $5 \mathrm{mg} / \mathrm{kg}$ body weight orally in sexually sluggish male rats; groups 3 and 4, received suspension of the hydroalcoholic extract of C. decidua at $100,200 \mathrm{mg} / \mathrm{kg}$ body weight orally in sexually sluggish male rats; group 5 (Per se) received suspension of the hydroalcoholic extract of C. decidua at $200 \mathrm{mg} / \mathrm{kg}$ body weight orally only to note the effect of extract only in sexually active male rats. Oral administration was carried out using a metal oropharyngeal cannula. Five rats in each group were monitored for sexual behavior after their daily doses on days $0,7,14,2128$. The experiments on animals were conducted in accordance with the principles of Institutional Animal Ethical Committee.

\subsection{Acute Toxicity Studies}

The acute toxicity of the extract was studied in adult male wistar rats. They were divided into five groups each consisting of five rats. The suspension of the extract was administered orally at four different doses of 500, 1000, 2000 and $4000 \mathrm{mg} / \mathrm{kg}$, respectively, to different groups of rats separately. Control animals received $10 \mathrm{ml} / \mathrm{kg}$ of distilled water orally. The animals were observed continuously for the initial $4 \mathrm{~h}$ for behavioral changes and mortality and intermittently for the next $6 \mathrm{~h}$ and then again at $24 \mathrm{~h}$ and $48 \mathrm{~h}$ after dosing. The behavior parameters observed were convulsion, hyperactivity, sedation, grooming, loss of righting reflex and increased respiration [8].

\subsection{Sexual Behavior Study}

Prior to the drug treatment, the male rats were trained separately with normal adult female rat for sexual experience. At that point, the male rats were partitioned into sexually active and sexually inactive groups, in view of their copulatory conduct. A male was considered sexually dynamic when it endeavored to mount any female brought into the cage. The normal mountings in ordinary male rats were observed to be 4-10 of every $5 \mathrm{~min}$. The animal showing below 4 mounts was considered as inactive. Sexually inactive male rats were selected for extract treated groups and standard group in the present study. The female 
sexual behavior is restricted to the estrous phase, that agrees with ovulation and during this time animal is said to be in heat. The estrous female stirs sexual enthusiasm for male rat by physical changes in the genital district and the creation of pheromones. These are sexual fragrances found in rats that deliver sensational sex-chasing conduct in rats. The female rats react to each mount with a lordosis reaction. This reaction happens when the female is responsive to mounting male and comprises of an angling of the back to a curved position with deviation along the side and the neck extended. The female rat with estrous cycle was affirmed by vaginal spread technique. A dropper with a drop of distilled water was brought into the rats's vagina and the discharges were gathered and were seen under microscope. Estrous cycle was affirmed when half or a greater amount of the cells were cornified. The sexually inactive male rats were divided into three groups and each contains five animals while control group and per se group includes sexually active male rats. Standard group (sildenafil citrate at $5 \mathrm{mg} / \mathrm{kg}$ p.o), hydroalcoholic extract of C. decidua at a dose of $100 \mathrm{mg} / \mathrm{kg}$ (p.o.) group and hydroalcoholic extract of C. decidua at a dose of $200 \mathrm{mg} / \mathrm{kg}$ (p.o.) treated groups includes the sexually inactive rats. The female animals were artificially brought into oestrus (heat) as the female rats allow mating only during the estrus phase. They were administered suspension of ethinyl oestradiol orally at the dose of $100 \mu \mathrm{g} /$ animal $48 \mathrm{~h}$ prior to the pairing plus progesterone injected subcutaneously, at the dose of 1 $\mathrm{mg} /$ animal $6 \mathrm{~h}$ before the experiment. The exceedingly responsive female (in estrous stage) was brought into the home cage of the male rats and the accompanying male sexual behavioral parameters were recorded amid a time of 30 min: Latency (time) of first mount, number of mounts, latency of first intromission, number of intromission, latency of ejaculation (time from intromission to ejaculation), number of ejaculations. All the groups were tested for copulatory behavior on 0,7 th, 14 th, 21 st and 28 th days [9].

\subsection{Statistical Analysis}

The data were represented as a mean \pm standard error of the mean (SEM). Statistical significance was carried out employing one-way analysis of variance (ANOVA) followed by Tukey's multiple comparison tests where $\mathrm{P}<0.05$ was considered statistically significant using Graph Pad Prism version 5.03 software.

\section{Results}

\subsection{Preliminary Qualitative Phytochemical Screening}

Preliminary qualitative phytochemical analysis of hydroalcoholic extract of $C$. decidua showed the presence of phenols, alkaloids, terpenoids, flavonoids, saponins, cardiac glycosides, steroids, tannins, and carbohydrates (Table 1).

\subsection{Effect of Acute Toxicity Studies}

The oral administration of hydroalcoholic extract of $C$. decidua did not provoke any gross behavioral changes or manifestations of toxic symptoms such as increased or decreased motor activity, loss of right reflex,ataxia, clonic convulsions,muscle relaxation spasticity, tremors, tonic extensions, lacrimation, salivation, weight loss, watery diarrhea, writhing and urination over a period of $48 \mathrm{~h}$. Hydroalcoholic extract of $C$. decidua was found to be non-lethal even at the maximum single dose of $4.0 \mathrm{~g} / \mathrm{kg}$. Dose of hydroalcoholic extract of $C$. decidua was selected on this basis and as per the earlier studies conducted by goyal et al 2009 [2] where $100 \mathrm{mg} / \mathrm{kg}$ and $200 \mathrm{mg} / \mathrm{kg}$ of $C$. decidua showed significant results $(\mathrm{P}<0.05)$ without any toxic effects at these doses.

\subsection{Effect of Sexual Behavior Study}

The observations of sexual behavior are presented in Table 2-6. Treatment with hydroalcoholic extract of $C$. decidua at different doses influenced the behavior of the treated animals in a dose-dependent manner. All the experimental groups significantly affected sexual behavior as compared with the control. C. decidua extract at the dose of $200 \mathrm{mg} / \mathrm{kg}$, significantly increased the Mounting Frequency (MF) $(\mathrm{P}<0.05)$ on day 21 and 28, Intromission Frequency (IF) on day $21(\mathrm{P}<0.05)$ and day $28(\mathrm{P}<0.01)$, Ejaculatory Latency (EL) on day $21(\mathrm{P}<0.01)$ and day 28 $(\mathrm{P}<0.01)$ and caused significant reduction in the Mounting Latency (ML) $(\mathrm{P}<0.01)$ on day 28 , Intromission Latency (IL) $(\mathrm{P}<0.01)$ on day 21 and 28, as compared to control group. The dose of $200 \mathrm{mg} / \mathrm{kg}$ of the extract significantly increased the MF on day $14(\mathrm{P}<0.05)$, day $21(\mathrm{P}<0.01)$, day $28(\mathrm{P}<0.001)$; IF on day $14(\mathrm{P}<0.05)$, day 21 and 28 $(\mathrm{P}<0.001)$; EL on day $7((\mathrm{P}<0.01)$, day $14(\mathrm{P}<0.01)$, day $21(\mathrm{P}<0.001)$, day $28(\mathrm{P}<0.001)$ and significantly decreased the ML on day $7(\mathrm{P}<0.01)$, day $14(\mathrm{P}<0.01)$, day $21(\mathrm{P}<0.001)$, day $28(\mathrm{P}<0.001)$; IL on day $7(\mathrm{P}<0.01)$, day $14(\mathrm{P}<0.05)$, day $21(\mathrm{P}<0.001)$, day $28(\mathrm{P}<0.001)$, in comparison with the control group. Per se group showed significant increase in MF on day $14(\mathrm{P}<0.05)$, day $21(\mathrm{P}<$ $0.01)$, day $28(\mathrm{P}<0.01)$; IF on day $28(\mathrm{P}<0.05)$; EL on day $14(\mathrm{P}<0.05)$, day $21(\mathrm{P}<0.001)$, day $28(\mathrm{P}<0.001)$ and significantly decreased the ML on day $7(\mathrm{P}<0.05)$, day $21(\mathrm{P}<0.001)$, day $28(\mathrm{P}<0.001)$; IL on day $7(\mathrm{P}<0.01)$, day $21(\mathrm{P}<0.001)$, day $28(\mathrm{P}<0.001)$ as compared to control group. Standard drug treated group gave highly significant increase in MF on day $7(\mathrm{P}<0.01)$, day $14(\mathrm{P}<$ $0.001)$, day $21(\mathrm{P}<0.001)$, day $28(\mathrm{P}<0.001)$; IF on day 7 $(\mathrm{P}<0.05)$, day $14(\mathrm{P}<0.001)$, day $21(\mathrm{P}<0.001)$, day $28(\mathrm{P}$ $<0.001)$; EL on day 7, 14, 21 and $28(\mathrm{P}<0.001)$ and significant decrease in ML and IL on day 7, 14, 21 and 28 $(\mathrm{P}<0.001)$ as compared to control. 
Table1. Representation of result of phytochemical studies in the hydroalcoholic extract of C. decidua

\begin{tabular}{|c|c|c|}
\hline S.No & Chemical test & Phytochemicals present \\
\hline 1 & $\begin{array}{l}\text { Test for phenolic compounds- } \\
\text { C. decidua extract dissolved in } 5 \mathrm{ml} \text { of distilled water and few drops of } 5 \% \text { ferric chloride were added. The } \\
\text { appearance of bluish black color indicated the presence of phenolic compounds. }\end{array}$ & $\begin{array}{l}\text { Showed the presence of } \\
\text { phenolic compounds }\end{array}$ \\
\hline 2 & $\begin{array}{l}\text { Test for flavonoids- } \\
\text { Few drops of dilute sodium hydroxide solution were added to the } C \text {. decidua extract }(0.5 \mathrm{ml}) \text { to give intense yellow } \\
\text { color which disappears after addition of dilute hydrochloride acid showed the presence of flavonoids. }\end{array}$ & $\begin{array}{l}\text { Showed the presence of } \\
\text { flavonoids }\end{array}$ \\
\hline 3 & $\begin{array}{l}\text { Test for terpenoids- } \\
\text { The extract }(0.5 \mathrm{mg}) \text { of } C \text {. decidua was added with few } \mathrm{ml} \text { of chloroform followed by concentrated sulphuric acid to } \\
\text { form a layer. Formation of the reddish-brown ring at the interface indicated the presence of terpenoids. }\end{array}$ & $\begin{array}{l}\text { Showed the presence of } \\
\text { terpenoids }\end{array}$ \\
\hline 4 & $\begin{array}{l}\text { Test for saponins- } \\
\text { C. decidua extract }(50 \mathrm{mg} \text { ) was diluted with distilled water and made up to } 20 \mathrm{ml} \text {. The suspension was shaken in a } \\
\text { graduated cylinder for } 15 \mathrm{~min} \text { using hands. Formation of } 2 \mathrm{~cm} \text { layer of foam layer indicated the presence of saponins. }\end{array}$ & $\begin{array}{l}\text { Showed the presence of } \\
\text { saponins }\end{array}$ \\
\hline 5 & $\begin{array}{l}\text { Test for alkaloids- } \\
\text { About } 50 \mathrm{mg} \text { of } C \text {. decidua extract was shaken with few } \mathrm{ml} \text { of dilute hydrochloric acid and filtered. Few drops of } \\
\text { Wagner's reagent were added to the side of the test tube. The appearance of reddish-brown precipitate indicated the } \\
\text { presence of alkaloids. }\end{array}$ & $\begin{array}{l}\text { Showed the presence of } \\
\text { alkaloids }\end{array}$ \\
\hline 6 & $\begin{array}{l}\text { Test for cardiac glycosides- } \\
\text { C. decidua extract }(50 \mathrm{mg} \text { ) was treated with } 2 \mathrm{ml} \text { of glacial acetic acid containing one drop of } 5 \% \text { ferric chloride, } \\
\text { followed by addition of } 1 \mathrm{ml} \text { of concentrated sulphuric acid. Formation of the brown ring at the interface is a feature of } \\
\text { cardenolide deoxy sugar and appearance of the violet ring below the brown ring and greenish ring in acetic acid layer } \\
\text { indicated the presence of cardiac glycosides. }\end{array}$ & $\begin{array}{l}\text { Showed the presence of } \\
\text { cardiac glycosides }\end{array}$ \\
\hline 7 & $\begin{array}{l}\text { Test for steroids- } \\
\text { C. decidua extract }(1 \mathrm{gm}) \text { was dissolved in chloroform }(10 \mathrm{ml}) \text { and added concentrated sulphuric acid }(1 \mathrm{ml}) \text { into the } \\
\text { test tube by wall sides. The color of the upper layer changed to red and the sulphuric acid layer showed yellow with } \\
\text { green fluorescence. This indicated the presence of steroids. }\end{array}$ & $\begin{array}{l}\text { Showed the presence of } \\
\text { steroids }\end{array}$ \\
\hline 8 & $\begin{array}{l}\text { Test for carbohydrates- } \\
\text { Molisch test: To } 2-3 \mathrm{ml} \text { of the aqueous. C. decidua extracts added two drops of alpha-naphthol solution in alcohol, } \\
\text { shaken and added conc. H2SO4 from the sides of the test tube. Violet ring was formed }\end{array}$ & $\begin{array}{l}\text { Showed the presence of } \\
\text { carbohydrates }\end{array}$ \\
\hline 9 & $\begin{array}{l}\text { Test for tannins- } \\
\text { C. decidua extract }(1 \mathrm{gm}) \text { dissolved in water in a test tube and diluted with chloroform and added acetic anhydride }(1 \\
\mathrm{mL}) \text {. Finally, sulphuric acid }(1 \mathrm{~mL}) \text { was added carefully to the side of the test tube to the solution. A green color was } \\
\text { formed which showed the presence of tannins }\end{array}$ & $\begin{array}{l}\text { Showed the presence of } \\
\text { tannins }\end{array}$ \\
\hline
\end{tabular}

Table 2. Effect of hydroalcoholic extract of C. decidua on mounting frequency in male rats

\begin{tabular}{|c|c|c|c|c|c|}
\hline \multirow{2}{*}{ Treatment Groups } & \multicolumn{5}{|c|}{ Mounting frequency (MF) } \\
\cline { 2 - 6 } & day 0 & day 7 & day 14 & day 21 & day 28 \\
\hline Control Group $(1 \mathrm{ml} / \mathrm{Kg})$ & $13.5 \pm 0.88$ & $13.5 \pm 0.88$ & $13 \pm 0.73$ & $13.83 \pm 1.08$ & $14.66 \pm 0.95$ \\
\hline Sildenafil citrate $(5 \mathrm{mg} / \mathrm{Kg})$ & $19.5 \pm 0.67$ & $20 \pm 0.57^{* *}$ & $20.5 \pm 0.67 * * *$ & $21.16 \pm 0.70^{* * *}$ & $22.5 \pm 0.76^{* * *}$ \\
\hline C. decidua $(100 \mathrm{mg} / \mathrm{kg})$ & $14.83 \pm 1.08$ & $15.16 \pm 0.75$ & $15.83 \pm 0.87$ & $18.16 \pm 0.47^{*}$ & $18.83 \pm 0.47^{*}$ \\
\hline C. decidua $(200 \mathrm{mg} / \mathrm{kg})$ & $16.83 \pm 1.54$ & $17.16 \pm 1.66$ & $18 \pm 1.85^{*}$ & $19.33 \pm 1.41^{* *}$ & $21 \pm 1.21^{* * *}$ \\
\hline Per se group $($ C. decidua $200 \mathrm{mg} / \mathrm{Kg})$ & $18 \pm 1.18$ & $18 \pm 1.18$ & $18.5 \pm 0.92^{*}$ & $19 \pm 0.77^{* *}$ & $19.5 \pm 0.76^{* *}$ \\
\hline
\end{tabular}

Tabular values are expressed as mean \pm SEM, $n=6$ (number of animals in each group); significant difference compared from control to extract treated groups and standard group. $* \mathrm{P}<0.05$, $* * \mathrm{P}<0.01 ; * * * \mathrm{P}<0.001$.

Table 3. Effect of hydroalcoholic extract of $C$. decidua on mounting latency in male rats

\begin{tabular}{|c|c|c|c|c|c|}
\hline \multirow{2}{*}{ Treatment Groups } & \multicolumn{5}{|c|}{ Mounting latency $(\mathrm{ML})$} \\
\cline { 2 - 6 } & day 0 & day 7 & day 14 & day 21 & day 28 \\
\hline Control Group $(1 \mathrm{ml} / \mathrm{Kg})$ & $135.96 \pm 2.93$ & $130.16 \pm 2.75$ & $116.25 \pm 2.05$ & $110.45 \pm 2.20$ & $93.36 \pm 1.37$ \\
\hline Sildenafil citrate $(5 \mathrm{mg} / \mathrm{Kg})$ & $109.14 \pm 4.06$ & $97.28 \pm 2.43 * * *$ & $80.44 \pm 2.81^{* * *}$ & $75.67 \pm 1.42^{* * *}$ & $61.42 \pm 1.64 * * *$ \\
\hline C. decidua $(100 \mathrm{mg} / \mathrm{kg})$ & $144.09 \pm 2.96$ & $124.72 \pm 2.8$ & $111.57 \pm 4.78$ & $98.67 \pm 1.65$ & $84.82 \pm 1.71^{* *}$ \\
\hline C. decidua $(200 \mathrm{mg} / \mathrm{kg})$ & $118.84 \pm 2.67$ & $110.45 \pm 3.49^{* *}$ & $99.17 \pm 3.22^{* *}$ & $84.29 \pm 2.37 * * *$ & $70.63 \pm 1.48^{* * *}$ \\
\hline Per se group $($ C. decidua $200 \mathrm{mg} / \mathrm{Kg})$ & $120.16 \pm 3.09$ & $113.50 \pm 4.13^{*}$ & $105.39 \pm 2.80$ & $87.32 \pm 2.39^{* * *}$ & $77.14 \pm 1.20^{* * *}$ \\
\hline
\end{tabular}

Tabular values are expressed as mean \pm SEM, $n=6$ (number of animals in each group); significant difference compared from control to extract treated groups and standard group. $* \mathrm{P}<0.05$, $* * \mathrm{P}<0.01 ; * * * \mathrm{P}<0.001$. 
Table 4. Effect of hydroalcoholic extract of C. decidua on Intromission latency in male rats

\begin{tabular}{|c|c|c|c|c|c|}
\hline \multirow{2}{*}{ Treatment Groups } & \multicolumn{5}{|c|}{ Intromission latency(IL) } \\
\cline { 2 - 6 } & day 0 & day 7 & day 14 & day 21 & day 28 \\
\hline $\begin{array}{c}\text { Control Group } \\
(1 \mathrm{ml} / \mathrm{Kg})\end{array}$ & $146.74 \pm 2.80$ & $140.30 \pm 2.64$ & $126.11 \pm 2.03$ & $120.39 \pm 2.18$ & $103.08 \pm 1.37$ \\
\hline $\begin{array}{c}\text { Sildenafil citrate } \\
(5 \mathrm{mg} / \mathrm{Kg})\end{array}$ & $116.97 \pm 3.79$ & $107.53 \pm 2.52^{* * *}$ & $87.70 \pm 2.40^{* * *}$ & $86.06 \pm 1.30^{* * *}$ & $71.68 \pm 1.71^{* * *}$ \\
\hline C. decidua $(100 \mathrm{mg} / \mathrm{kg})$ & $154.17 \pm 2.98$ & $133.33 \pm 2.73$ & $122.84 \pm 4.60$ & $108.94 \pm 1.95^{* *}$ & $94.84 \pm 1.68^{* *}$ \\
\hline C. decidua $(200 \mathrm{mg} / \mathrm{kg})$ & $129.34 \pm 2.84$ & $121.99 \pm 3.33^{* *}$ & $109.09 \pm 3.26^{*}$ & $94.36 \pm 2.31^{* * *}$ & $80.64 \pm 1.45^{* * *}$ \\
\hline Per se group $($ C. decidua $200 \mathrm{mg} / \mathrm{Kg})$ & $129.74 \pm 2.66$ & $123.39 \pm 4.18^{* *}$ & $113.79 \pm 3.69$ & $98.78 \pm 2.53^{* * *}$ & $87.14 \pm 1.18^{* * *}$ \\
\hline
\end{tabular}

Tabular values are expressed as mean $\pm \mathrm{SEM}, \mathrm{n}=6$ (number of animals in each group); significant difference compared from control to extract treated groups and standard group. $* \mathrm{P}<0.05, * * \mathrm{P}<0.01 ; * * * \mathrm{P}<0.001$.

Table 5. Effect of hydroalcoholic extract of $C$. decidua on Intromission frequency in male rats

\begin{tabular}{|c|c|c|c|c|c|}
\hline \multirow{2}{*}{ Treatment Groups } & \multicolumn{5}{|c|}{ Intromission frequency (IF) } \\
\cline { 2 - 6 } & day 0 & day 7 & day 14 & day 21 & day 28 \\
\hline Control Group $(1 \mathrm{ml} / \mathrm{Kg})$ & $9.5 \pm 0.99$ & $11.16 \pm 0.54$ & $11.16 \pm 0.60$ & $11.66 \pm 0.84$ & $11.16 \pm 0.65$ \\
\hline Sildenafil citrate $(5 \mathrm{mg} / \mathrm{Kg})$ & $14.16 \pm 1.17$ & $15.16 \pm 0.87^{*}$ & $17.66 \pm 0.84^{* * *}$ & $19.83 \pm 1.30^{* * *}$ & $21.66 \pm 1.61^{* * *}$ \\
\hline C. decidua $(100 \mathrm{mg} / \mathrm{kg})$ & $10.83 \pm 0.60$ & $11.16 \pm 0.70$ & $13.83 \pm 1.45$ & $16.16 \pm 0.70^{*}$ & $16.5 \pm 0.76^{* *}$ \\
\hline C. decidua $(200 \mathrm{mg} / \mathrm{kg})$ & $11.66 \pm 1.20$ & $13.33 \pm 0.66$ & $15.33 \pm 1.02 *$ & $17.5 \pm 0.67^{* * *}$ & $19.5 \pm 0.76^{* * *}$ \\
\hline Per se group $($ C. decidua $200 \mathrm{mg} / \mathrm{Kg})$ & $10.16 \pm 1.01$ & $11.33 \pm 1.14$ & $12.16 \pm 0.83$ & $12.83 \pm 0.83$ & $15.33 \pm 0.66^{*}$ \\
\hline
\end{tabular}

Tabular values are expressed as mean \pm SEM, $\mathrm{n}=6$ (number of animals in each group); significant difference compared from control to extract treated groups and standard group. $* \mathrm{P}<0.05, * * \mathrm{P}<0.01 ; * * * \mathrm{P}<0.001$.

Table 6. Effect of hydroalcoholic extract of C. decidua on Ejaculation latency in male rats

\begin{tabular}{|c|c|c|c|c|c|}
\hline \multirow{2}{*}{ Treatment Groups } & \multicolumn{5}{|c|}{ Ejaculation latency (EL) } \\
\cline { 2 - 6 } & day 0 & day 7 & day 14 & day 21 & day 28 \\
\hline $\begin{array}{c}\text { Control Group } \\
(1 \mathrm{ml} / \mathrm{Kg})\end{array}$ & $176.16 \pm 3.63$ & $177.66 \pm 4.82$ & $180.5 \pm 4.08$ & $187.66 \pm 3.98$ & $197.33 \pm 4.01$ \\
\hline $\begin{array}{c}\text { Sildenafil citrate } \\
(5 \mathrm{mg} / \mathrm{Kg})\end{array}$ & $261.83 \pm 18.62$ & $265.5 \pm 19.39 * * *$ & $270.33 \pm 20.80^{* * *}$ & $289.83 \pm 9.47 * * *$ & $299.16 \pm 9.05 * * *$ \\
\hline C. decidua $(100 \mathrm{mg} / \mathrm{kg})$ & $209.16 \pm 7.73$ & $212.5 \pm 7.81$ & $221 \pm 7.85$ & $235 \pm 7.88^{* *}$ & $243.83 \pm 7.05 * *$ \\
\hline C. decidua $(200 \mathrm{mg} / \mathrm{kg})$ & $237.66 \pm 8.60$ & $244 \pm 8.65^{* *}$ & $253.16 \pm 8.68^{* *}$ & $261.5 \pm 6.58^{* * *}$ & $274 \pm 7.02^{* * *}$ \\
\hline Per se group $($ C. decidua $200 \mathrm{mg} / \mathrm{Kg})$ & $220.33 \pm 7.33$ & $230.83 \pm 7.98$ & $239.33 \pm 8.32^{* *}$ & $249.16 \pm 10.31^{* * *}$ & $259.16 \pm 10.64 * * *$ \\
\hline
\end{tabular}

Tabular values are expressed as mean $\pm \mathrm{SEM}, \mathrm{n}=6$ (number of animals in each group); significant difference compared from control to extract treated groups and standard group. ${ }^{*} \mathrm{P}<0.05$, $* * \mathrm{P}<0.01 ; * * * \mathrm{P}<0.001$.

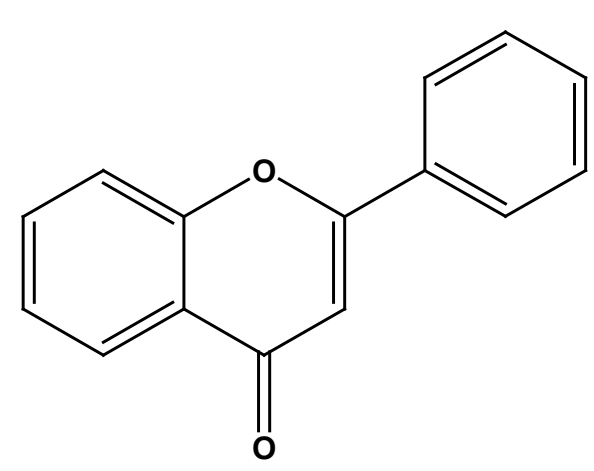

(A) Flavonoid

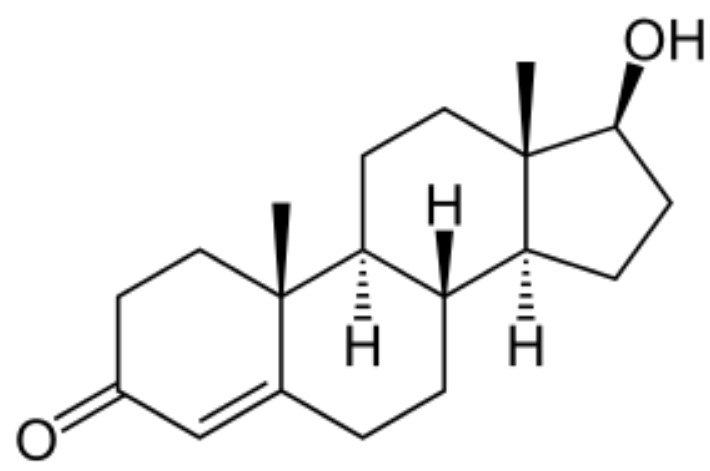

(B) Steroid 


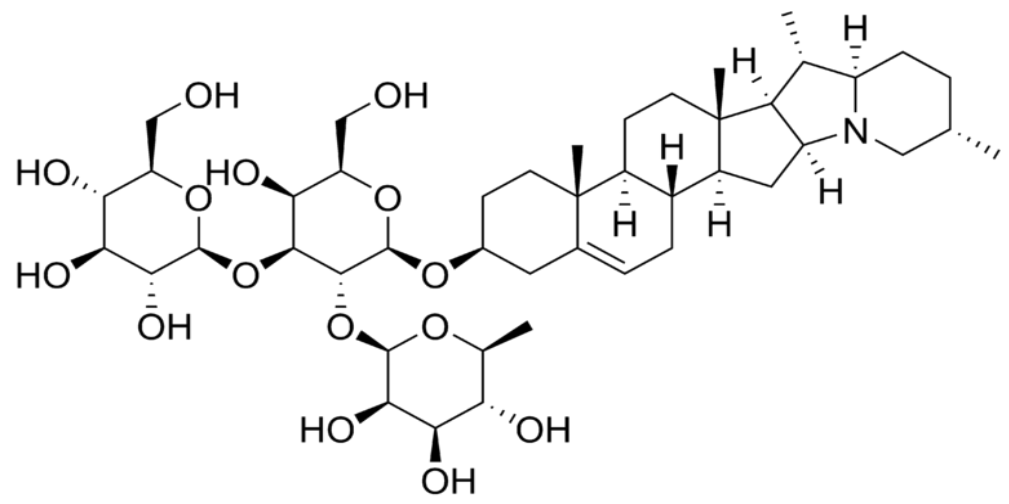

(C) Saponin<smiles>COC1=CC(OC2CC(C3=CC(=O)NCC3CNCC3CCNC(=O)C3=CC3CCC(O)=CC3OC)CCC2O)=CC(O)C1</smiles>

(D) Capparisine alkaloid

Figure (A-D). Representation of possible phytoconstituents responsible for the aphrodisiac activity found in C. decidua plant

\section{Discussions}

In the present study, hydroalcoholic extract of $C$. decidua was tested in animal experimentation for its effect on sexual behaviour, and sildenafil citrate was used as the standard referent. Mating behaviour test revealed that the extract of $C$. decidua significantly increased the Mounting Frequency (MF) and Intromission Frequency (IF) as compared to control but less than that of the standard drug. The (MF) and (IF) are considered as the exponents of sexual desire and potency. So, it indicates that the test drug possesses a sexual function improving effect. The extract of $C$. decidua significantly increased the EL as compared to control group animals, whereas a highly significant increase was observed with the standard drug sildenafil citrate. The $C$. decidua extract was found to produce a significant reduction in the Mounting Latency (ML) and Intromission Latency (IL) as compared to control while a highly significant decrease was found in ML of animals treated with sildenafil citrate. This is also an evidence of the sexual function improving effect of the $C$. decidua extract. The significant increase in the Ejaculatory Latency (EL) indicates that the extract and standard drug prolonged the duration of coitus. These findings demonstrate that the extract produces a striking improvement of general sexual execution of rats in experimental groups. Moreover the proceptive behaviours were seen in the animals like darting, hopping and lordosis by female rats and precopulatory behavior in male rats as well which implicates the sexual arousal between opposite sex rats. Mount Frequency and Intromission Frequency are useful factors of sexual strength, sexual desire and potency. The number of mount (MF) reflects sexual motivation, and rise in the number of intromission (IF) shows the efficiency of erection.Some of the medicinal plants are effective as aphrodisiac through mechanisms such as vasodilation, generation of nitric oxide, elevation of androgens and gonadotropins [10].In the previous studies it is seen that Dehydroepiandrosterone (DHEA), a major circulating steroid (Figure B) in the plasma, and a common precursor for both androgens and estrogens and its subsequent conversions to testosterone and its metabolites responsible for the effective masculine behavior in rats [11].The involvement of saponins (Figure C) in the biosynthesis of DHEA boosts the level of testosterone and therefore triggers the sexual desire in male rats [12]. Steroidal nature of saponins makes it possible to act as intermediary in androgen synthesis where saponin binds to hormone receptor and undergoes conformational 
change to yield androgen production. Similarly the flavonoids (Figure A) due to its antioxidant property alter androgen levels and are responsible for the enhanced male sexual behavior. Alkaloids (Figure D) are reported to have ergogenic properties act on central nervous system by causing vasodilation of the blood vessels through the production of endothelium dependent releasing factor i.e. nitric oxide and allowing erection or arouses steroidogenesis in the testes of the animals. Alkaloids also act on peripheral nervous system by relaxing Corpus cavernosum smooth muscle in the penis of the male rats[13].

In the previous studies ethanolic extract of rhizomes Curculigo orchioides evaluated for effect on sexual behavior in rats. $100 \mathrm{mg} / \mathrm{kg}$ of extract change significantly the sexual behavior pattern assessed by parameters such as mating performance, mount frequency and mount latency. The rhizome extract markedly affected sexual behavior of rats as seen in reduction of mount latency, an increase in mount frequency and enhanced attractability towards female rats [14].During the phytochemical screening of extract of $C$. decidua there was occurrence of flavonoids, alkaloids, saponins and many other phytochemicals. Thus, the resultant aphrodisiac activity of the test drug might be attributed to phytochemicals like flavonoids, alkaloids, saponins. Moreover, further research is also needed for the distinguishing proof of its dynamic constituents responsible for sexual function improving activities and the mechanism by which it increases sexual function.

\section{Conclusions}

Overall, our results have revealed that the hydroalcoholic extract of C. decidua at the doses of 100 and $200 \mathrm{mg} / \mathrm{kg}$ body weight could be used as a stimulator of sexual behaviour in male rats. The present study thus supports the acclaimed aphrodisiac use of this plant in herbal medicine. The aphrodisiac effect of the plant extract may be due to the presence of alkaloids, saponins, flavonoids through a multitude of central and peripheral ways.

\section{Acknowledgements}

The authors are grateful to Dr. Vikram Sharma, Department of Pharmacy, SMAS, Galgotias University, Greater Noida for his appropriate and constructive suggestions.

\section{Conflict of Interest}

Authors declare that there are no conflicts of interest.

\section{REFERENCES}

[1] C. JianFeng, Z. PengYing, X. ChengWei, H. TaoTao et al, "Effect of aqueous extract of Arctium lappa L. (burdock) roots on the sexual behavior of male rats," $B M C$ Complement. Altern. Med., 2012;12(1): 1-8.

[2] M. Goyal, B. P. Nagori, and D. Sasmal, "Sedative and anticonvulsant effects of an alcoholic extract of Capparis decidua," J. Nat. Med.,2009; 63(4):375-379.

[3] N. Tlili, W. Elfalleh, E. Saadaoui, A. Khaldi, S. Triki, and N. Nasri, "The caper (Capparis L.): Ethnopharmacology, phytochemical and pharmacological properties," Fitoterapia. 2011; 82(2): 93-101.

[4] B. Sharma, R. Salunke, C. Balomajumder, S. Daniel, and P. Roy, "Anti-diabetic potential of alkaloid rich fraction from Capparis decidua on diabetic mice," $J$. Ethnopharmacol.2010; 127(2): 457-462.

[5] T. Gull, F. Anwar, B. Sultana, M. A. C. Alcayde, and W. Nouman, "Capparis species: A potential source of bioactives and high-value components: A review," Ind. Crops Prod. 2015; 67: 81-96.

[6] P. K. Dhakad, P. K. Sharma, and S. Kumar, "A Review on Ethnobiological \& Medicinal Potential of Capparaceae Family Plant: Capparis decidua ( Forssk .) Edgew," $A d v$. Pharmacol. Pharm.2016; 4(3): 27-39.

[7] Z. Khanam, C. S. Wen, and I. U. H. Bhat, "Phytochemical screening and antimicrobial activity of root and stem extracts of wild Eurycoma longifolia Jack (Tongkat Ali)," J. King Saud Univ. - Sci., 2015; 27(1): 23-30.

[8] P. M. Herman, B. M. Craig, and O. Caspi, "Is complementary and alternative medicine (CAM) cost-effective? a systematic review," BMC Complement. Altern. Med. 2005; 5(11): 1-15.

[9] G. Asuntha, Y. Prasanna Raju, V. Harini Chowdary, K. R. Vandana, R. Arun, and K. V. S. R. G. Prasad, "Pharmacological profiling of Argemone mexicana for its aphrodisiac potentials in male Wistar rats," Asian Pacific J. Reprod. 2014; 3(2):110-115.

[10] T. M. Mills, C. M. Reilly, and R. W. Lewis, "Androgens and penile erection: a review," Journal of Andrology. 1996; 17(6): 633-638.

[11] M. D. Majewska, "Neuronal activities of dehydroepiandrosterone," in Dehydroepiandrosterone (DHEA) and Aging, F. L. Bellino, R. A. Davies, P. J. Hornsby, D. H. Lavrin, and J. E. Nestler, Eds.,1995; 774: 111-120, The New York Academy of Sciences.

[12] K. Gauthaman and P. G. Adaikan, "The hormonal effects of Tribulus terrestris and its role in the management of male erectile dysfunction - an evaluation using primates, rabbit and rat," Phytomedicine. 2008; 15(1): 44-54.

[13] M. T. Yakubu and M. A. Akanji, "Effect of aqueous extract of massularia acuminata stem on sexual behaviour of male wistar rats," Evidence-based Complement. Altern. Med. 2011:1-11.

[14] N. S. Chauhan, C. V. Rao, and V. K. Dixit, "Effect of Curculigo orchioides rhizomes on sexual behaviour of male rats," Fitoterapia, 2007; 78(7): 530-534. 